\title{
Systemic inflammation is associated with exaggerated skeletal muscle protein catabolism in maintenance hemodialysis patients
}

Serpil M. Deger, ${ }^{1,2,3}$ Adriana M. Hung, ${ }^{1,2,3}$ Jorge L. Gamboa, ${ }^{4}$ Edward D. Siew, ${ }^{1,2,3}$ Charles D. Ellis, ${ }^{1,3}$ Cindy Booker, ${ }^{1,2,3}$ Feng Sha, ${ }^{1}$ Haiming Li, ${ }^{1}$ Aihua Bian, ${ }^{5}$ Thomas G. Stewart, ${ }^{5}$ Roy Zent, ${ }^{1,3}$ William E. Mitch, ${ }^{6}$ Naji N. Abumrad, ${ }^{7}$ and T. Alp Ikizler ${ }^{1,2,3}$

'Division of Nephrology, Vanderbilt University Medical Center (VUMC), Nashville, Tennessee, USA. ${ }^{2}$ CSRD\&D, Veterans Administration Tennessee Valley Healthcare System, Nashville, Tennessee, USA. ${ }^{3}$ Vanderbilt Center for Kidney Disease, ${ }^{4}$ Division of Clinical Pharmacology, and ${ }^{5}$ Department of Biostatistics, VUMC, Nashville, Tennessee, USA. ${ }^{6}$ Selzman Institute for Kidney Health, Baylor College of Medicine, Department of Medicine, Houston, Texas, USA. 'Department of Surgery, VUMC, Nashville, Tennessee, USA.

BACKGROUND. Systemic inflammation and muscle wasting are highly prevalent and coexist in patients on maintenance hemodialysis (MHD). We aimed to determine the effects of systemic inflammation on skeletal muscle protein metabolism in MHD patients.

METHODS. Whole body and skeletal muscle protein turnover were assessed by stable isotope kinetic studies. We incorporated expressions of E1, E214K, E3 $\alpha$ l, E3 $\alpha$ ll, MuRF-1, and atrogin-1 in skeletal muscle tissue from integrin $\beta 1$ gene KO CKD mice models.

RESULTS. Among 129 patients with mean ( \pm SD) age $47 \pm 12$ years, $74 \%$ were African American, $73 \%$ were male, and $22 \%$ had diabetes mellitus. Median high-sensitivity C-reactive protein (hsCRP) concentration was 13 (interquartile range $0.8,33$ ) $\mathrm{mg} / \mathrm{l}$. There were statistically significant associations between hs-CRP and forearm skeletal muscle protein synthesis, degradation, and net forearm skeletal muscle protein balance $(P<0.001$ for all). The associations remained statistically significant after adjustment for clinical and demographic confounders, as well as in sensitivity analysis, excluding patients with diabetes mellitus. In attempting to identify potential mechanisms involved in this correlation, we show increased expressions of E1, E214K, E3 $\alpha$ l, E3 $\alpha$ Il, MuRF-1, and atrogin-1 in skeletal muscle tissue obtained from an animal model of chronic kidney disease.

CONCLUSION. These data suggest that systemic inflammation is a strong and independent determinant of skeletal muscle protein homeostasis in MHD patients, providing rationale for further studies using anticytokine therapies in patients with underlying systemic inflammation.

FUNDING. This study was in part supported by NIH grants R01 DK45604 and 1K24 DK62849, the Clinical Translational Science Award UL1-TR000445 from the National Center for Advancing Translational Sciences, the Veterans Administration Merit Award 101 CX000414, the SatelliteHealth Normon Coplon Extramural Grant Program, and the FDA grant 000943.

Conflict of interest: The authors have declared that no conflict of interest exists.

Submitted: May 31, 2017 Accepted: October 12, 2017 Published: November 16, 2017

Reference information: JCI Insight. 2017;2(22):e95185. https://doi.org/10.1172/jici. insight.95185.

\section{Introduction}

Systemic inflammation and muscle wasting are highly prevalent in end-stage renal disease (ESRD) patients undergoing maintenance hemodialysis (MHD). Epidemiological data suggest that the severity of systemic inflammation is closely associated with markers of poor nutrition and could play a causal role in muscle wasting observed in MHD patients. Proinflammatory cytokines can increase muscle protein degradation through suppression of insulin receptor substrate-1-associated (IRS-1-associated) phosphatidylinositol 3 kinase (PI3K) activity, resulting in stimulation of ubiquitin-proteasome proteolytic (UPP) system and caspase-3 activation, an initial step of muscle protein degradation. Studies to 
determine whether this mechanistic link exists in humans with advanced kidney disease are few and limited by design and sample size.

In a series of experiments, we sought to test the hypothesis that higher levels of systemic inflammation are associated with increased skeletal muscle protein degradation. We examined skeletal muscle and whole body protein homeostasis using stable isotope methodology in $129 \mathrm{MHD}$ patients. We then examined selected markers of metabolic signaling in skeletal muscle tissue obtained from an established mouse model of chronic kidney disease $(\mathrm{CKD})$. The results from the metabolic studies suggest that systemic inflammation is a strong and independent determinant of protein homeostasis, especially in the skeletal muscle compartment in MHD patients.

\section{Results}

Higher state of systemic inflammation is associated with unfavorable skeletal muscle and whole body protein turnover balance in MHD patients. We retrospectively analyzed the association between high-sensitivity C-reactive protein (hs-CRP) levels and skeletal muscle and whole body protein turnover components over 129 MHD patients who participated in a variety of metabolic studies at VUMC and Veterans Affairs Tennessee Valley Health Care System (VA-THS) between July 1998 and March 2011. All patients underwent stable isotope metabolic study using the same protocol (Figure 1) after an 8-hour fasting, where we obtained forearm skeletal muscle and whole body protein turnover rates.

Table 1 depicts the demographic and clinical characteristics of the study population. The mean $( \pm$ SD) age of study patients was $47 \pm 12$ years. Patients were predominantly African American (74\%), 73\% were male, and $22 \%$ had diabetes mellitus (DM) according to the American Diabetes Association (ADA) criteria or based on medical history obtained from the charts. The median duration of MHD was 54 (interquartile range [IQR] 16, 96) months. The median BMI was 27 (IQR 23, 34) kg/m². Median hs-CRP level was 13 (IQR 0.8, 33) mg/1.

Forearm skeletal muscle protein homeostasis. Figure 2 depicts the median [IQR] forearm overnight fasting skeletal muscle protein synthesis, breakdown, and net balance rates of study subjects. As expected, forearm skeletal muscle protein breakdown $(69[32,117] \mu \mathrm{g} / 100 \mathrm{ml} / \mathrm{min})$ was higher compared with synthesis $(57[14,94] \mu \mathrm{g} / 100 \mathrm{ml} / \mathrm{min})$ resulting in a negative net skeletal muscle protein balance $(-21$ $[-58,21] \mu \mathrm{g} / 100 \mathrm{ml} / \mathrm{min})$. We then categorized the patients into quartiles based on their hs-CRP values: quartile 1 as normal: $0.1-0.7 \mathrm{mg} / 1$, quartile 2 as medium: $0.8-12.9 \mathrm{mg} / 1$, quartile 3 as high: $13.0-33.2$ $\mathrm{mg} / 1$, and quartile 4 as severe: 33.3-59.0 mg/1. As shown in Figures 3, A-C, there were statistically significant associations between hs-CRP quintiles and forearm skeletal muscle protein synthesis (Figure $3 \mathrm{~A}$ ), degradation (Figure 3B), and net forearm skeletal muscle protein balance (Figure $3 \mathrm{C})(P<0.001$ for all). The medians for each group (IQR) are shown in Table 2.

Spearman correlation analysis showed an inverse (negative) correlation between hs-CRP (log scale; see Supplemental Figure 1; supplemental material available online with this article; https://doi.org/10.1172/ jci.insight.95185DS1) and forearm skeletal muscle protein synthesis (Spearman rank-order coefficient $\left[r_{s}\right]=$ $-0.52, P<0.001$, Figure 4A) whereas a direct (positive) correlation was observed with protein degradation $(r$ $=0.54, P<0.001$, Figure 4B). The inverse (negative) correlation between hs-CRP and net protein balance was remarkably robust $\left(r_{s}=-0.96, P<0.001\right)$ (Figure $4 \mathrm{C}$ ). These data indicated worsening systemic inflammation, which is associated with simultaneous increased skeletal muscle breakdown and suppressed protein synthesis, resulting in an exaggerated level of net skeletal muscle catabolism at the highest quintiles of hs-CRP.

In order to examine whether there are any confounders of this robust association between systemic inflammation and skeletal muscle homeostasis, we performed a multivariate linear regression analysis. Based on the sample size available, we were able to incorporate up to 10 variables in the model without overfitting. Since insulin resistance and diabetes are biologically linked, we created 2 multivariate models, first with diabetes (Model 1) and second replacing diabetes with homeostasis model assessment of insulin resistance (HOMA-IR) as a marker of insulin resistance (Model 2). Both models included age, sex, race, time since initiation of dialysis (vintage), serum albumin, fat mass (FM), and hs-CRP levels. As shown in Table 3, hs-CRP remained statistically significantly associated with all components of skeletal muscle protein turnover in Model 1; 95\% CI, $-65(-119,-11)$ for protein synthesis; 95\% CI, 40 $(-10,91)$ for protein breakdown; and 95\% CI, $-105(-137,-74)$ for net protein balance (all overall $P<$ 0.001). Similar to Model 1, hs-CRP was still statistically significantly associated with all components of protein metabolism in Model 2, as well: $95 \% \mathrm{CI},-38(-94,18)$ for protein synthesis; $95 \% \mathrm{CI}, 64$ $(13,115)$ for protein breakdown; and 95\% CI, $-103(-138,-68)$ for net protein balance (all overall $P$ $<0.001)$. These data suggest that systemic inflammation is associated with protein breakdown through 


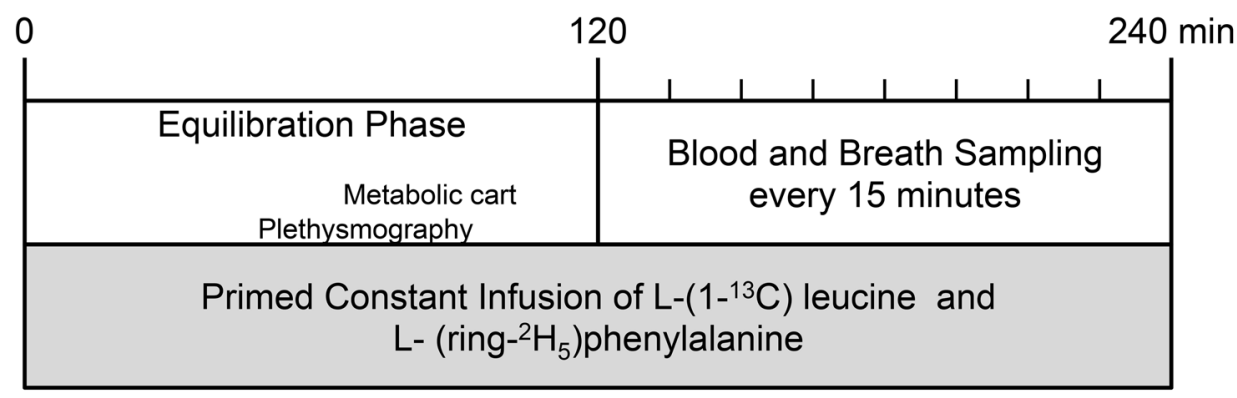

Figure 1. The diagram of metabolic study protocol. The patients were admitted to General Clinical Research Center the day before the study. They received a meal from bionutrition services after admission and remained in a fasting state for at least 10 hours prior to the initiation of the study. All metabolic studies were performed at least 24 hours after the most recent hemodialysis procedure. A primed constant infusion of $\mathrm{L}-\left(1-{ }^{13} \mathrm{C}\right)$ leucine and $\mathrm{L}-\left(\mathrm{ring}-{ }^{2} \mathrm{H}_{5}\right)$ phenylalanine was maintained throughout the metabolic study. Metabolic cart and plethysmography measurements were performed during the equilibration period. Blood and breath sampling were performed during the steady-state period.

mechanisms that are independent of the other conditions such as age and diabetes that are known to associate with protein energy wasting in the setting of advanced kidney disease.

Whole body protein homeostasis. While $40 \%$ of whole body protein turnover is determined by skeletal muscle tissue; there are other (visceral) proteins that influence the overall whole body protein homeostasis, with serum albumin being the most relevant (1). Accordingly, we examined the relationship between levels of systemic inflammation and whole body protein balance in our study cohort.

The median [IQR] whole body protein synthesis rate was $5[4,5] \mathrm{mg} / \mathrm{kg}$.fat free mass $/ \mathrm{min}$, whole body protein breakdown rate was $4[3,4] \mathrm{mg} / \mathrm{kg}$.fat free mass $/ \mathrm{min}$ and the whole body net protein balance was 0.4 $[-0.4,0.7] \mathrm{mg} / \mathrm{kg}$.fat free mass $/ \mathrm{min}$ in the study patients. The distribution of the whole body protein turnover markers by hs-CRP quintiles did not show any significant differences for whole body protein synthesis $(P=$ $0.65)$, whole body protein breakdown $(P=0.30)$, or whole body net protein balance rates $(P=0.12)$. Spearman correlation analysis showed no statistically significant correlations between hs-CRP and whole body protein turnover components $(\mathrm{r}=-0.06, P=0.48$ for whole body protein synthesis; $\mathrm{r}=0.06, P=0.47$ for whole body protein breakdown; and $\mathrm{r}=-0.02, P=0.79$ for net whole body protein balance). Multivariate models also showed no statistically significant association between hs-CRP and any component of whole body protein turnover. These data suggest that systemic inflammation may not influence whole body protein homeostasis as prominently as skeletal muscle, although further studies are necessary to delineate these differences.

Sensitivity analysis excluding patients with DM. Insulin resistance is prevalent in CKD patients both with and without DM. In CKD, postreceptor abnormalities, such as decreased activity of PI3K, play a critical role in the impairment of insulin signaling, which is suggested as a primary mediator of muscle protein catabolism in advanced kidney disease. MHD patients with suboptimally controlled type 2 diabetes have a higher rate of muscle protein loss than HD patients without diabetes, a catabolic state that can be detected even in MHD patients with insulin resistance (2). In order to exclude any potential impact of obvious abnormalities in insulin signaling, we repeated all analyses after excluding 29 diabetic patients. Results for all analyses were consistent with the primary results (Supplemental Figure 2, Supplemental Figure 3, and Supplemental Tables 1-3). These data suggest that the adverse effects of systemic inflammation are equally observed in MHD patients with or without diabetic kidney disease.

Mechanisms of inflammation-related catabolism in advanced kidney disease. The ubiquitin-proteasome system (UPS) is one of the pivotal components of the regulation of skeletal muscle protein breakdown in CKD $(3,4)$. In order to examine the contributions of UPS and systemic inflammation in the development of skeletal muscle protein degradation in CKD, we performed studies in skeletal muscle tissue obtained from an established mouse model of kidney disease and tissue obtained from a subset of MHD patients who also completed metabolic studies.

The mouse model of CKD was induced by genetically deleting $\beta 1$ integrin from either the podocyte or the developing ureteric bud during mouse development by crossing a floxed $\beta 1$ integrin mouse with a podocin or HoxB7 Cre mouse, respectively $(5,6)$. Aged-matched littermates homozygous for the floxed integrin $\beta 1$ gene, but lacking Cre ( $\beta 1^{\text {flox/flox }}$ mice), were used as controls. The mice lacking $\beta 1$ integrin 
Table 1. Characteristics of 129 MHD Patients

\begin{tabular}{|c|c|}
\hline Variable & $n=129$ \\
\hline \multicolumn{2}{|l|}{ Demographics } \\
\hline Age (years, mean \pm SD) & $47 \pm 12$ \\
\hline \multicolumn{2}{|l|}{$\operatorname{Sex}(n, \%)$} \\
\hline Female & $35(27 \%)$ \\
\hline Male & $94(73 \%)$ \\
\hline \multicolumn{2}{|l|}{ Race $(n, \%)$} \\
\hline African American & $96(74 \%)$ \\
\hline European descent & $30(24 \%)$ \\
\hline Asian & $3(2 \%)$ \\
\hline \multicolumn{2}{|l|}{ Etiology of ESRD } \\
\hline Diabetes mellitus & $14(11 \%)$ \\
\hline Hypertension & $88(68 \%)$ \\
\hline Polycystic kidney disease & $3(2 \%)$ \\
\hline Other & $6(5 \%)$ \\
\hline Unknown & $18(14 \%)$ \\
\hline Dialysis vintage (months, median, IQR) & $54(16,96)$ \\
\hline \multicolumn{2}{|l|}{ Hemodialysis access $(n, \%)$} \\
\hline Arterio-venous fistula & $67(52 \%)$ \\
\hline Arterio-venous graft & $62(42 \%)$ \\
\hline \multicolumn{2}{|l|}{ Body composition } \\
\hline BMI (kg/m², median, IQR) & $27(23,34)$ \\
\hline Fat mass (kg, median, IQR) & $25(17,36)$ \\
\hline Lean mass (kg, median, IQR) & $52(47,58)$ \\
\hline \multicolumn{2}{|l|}{ Laboratory markers } \\
\hline Serum creatinine (mg/dl, median, IQR ) & $8(5,12)$ \\
\hline Prealbumin (mg/dl, median, IQR) & $33(23,38)$ \\
\hline Albumin (g/dl, median, IQR) & $3.7 \pm 0.5$ \\
\hline Plasma bicarbonate (mg/dl, mean \pm SD) & $24 \pm 7$ \\
\hline \multicolumn{2}{|l|}{ Carbohydrate metabolism } \\
\hline Diabetes mellitus (n, \%) & $29(22 \%)$ \\
\hline HOMA-IR & $1.5(0.8,2.8)$ \\
\hline \multicolumn{2}{|l|}{ Inflammatory and metabolic markers } \\
\hline hs-CRP (mg/l, median, IQR) & $13(0.8,33)$ \\
\hline
\end{tabular}

in the podocytes developed fatal proteinuric renal failure by approximately 8 weeks of age, while the $\mathrm{HoxB} 7 \mathrm{Cre}$ mice developed severe dysplastic dysmorphic kidneys, resulting in death from renal failure not associated with proteinuria by the same age.

$\beta 1$ Hom-Pod mice had smaller and paler kidneys and displayed skeletal muscle atrophy $(5,6)$, and they weighed less compared with WT mice (weight $16.1 \pm$ $4.3 \mathrm{gm}$ versus $20.5 \pm 5.1 \mathrm{gm}$, respective1y); they also had statistically significantly increased albumin/creatinine ratio (ACR) $(7.49 \mathrm{~g} / \mathrm{g}$ versus $1.14 \mathrm{~g} / \mathrm{g}$, respectively, $P=0.005)$. $\beta 1$ Hom-Hox mice presented with same characteristics (weight $18.5 \pm 3.8 \mathrm{gm}$ ) as the $\beta 1$ Hom-Pod mice, except that they did not have proteinuria (ACR $1.16 \mathrm{mg} / \mathrm{g}$ ) (Figure 5B). BUN concentrations were numerically higher in Hom-Pod and Hom-Hox mice compared with WT (Figure 5A).

Serum pro- and antiinflammatory cytokine concentrations. There were numerical differences in serum concentrations of serum IL-6, IL-10, and TNF- $\alpha$ between $\beta 1$ Hom-Hox $(n=6)$, $\beta 1$ Hom-Pod $(n=$ $6)$, and WT $(n=6)$ mice, although none of these differences reached statistical significance (Figure 6A).

Tissue markers of protein breakdown and synthesis. We examined protein expressions of pAkt, Ubiquitin (Ub) conjugates, and 20S proteasome subunits $\alpha 1,2,3,5$, 6 and 7 by immunoblotting in $6 \beta 1 \mathrm{Hom}-$ Pod, $6 \beta 1 \mathrm{Hom}$-Hox and 6 WT mice (Fig-

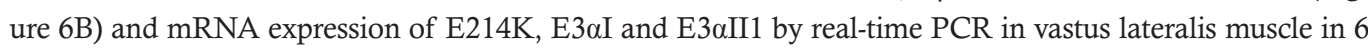
$\beta 1$ Hom-Pod, $6 \beta 1$ Hom-Hox and 6 WT mice (Figure 7A). We also examined mRNA expression of MuRF-1 and atrogin- 1 by real-time PCR in 6 B1Hom-Pod and 6 WT mice (Figure 7B).The protein expression of $\mathrm{Ub}$ conjugates and 20S proteasome subunits $\alpha 1,2,3,5,6$, and 7 were highly statistically significantly elevated in Hom-Pod mice compared with WT or Hom-Hox mice $(P<0.001)$ for all). Similar results were observed when comparing pAKT expression between the groups (Figure 6B). The mRNA expressions of E214k, E3aI, and E3aII were statistically significantly higher in Hom-Pod mice compared with WT mice $(P<0.003$ for all $)$ (Figure 7A). MuRF-1 and atrogin-1 expressions were numerically higher in Hom-Pod mice compared with WT mice, with difference in atrogin-1 reaching statistical significance only (Figure 7B).

\section{Discussion}

The results presented herein strongly suggest that systemic inflammation is a critical determinant of skeletal muscle protein homeostasis in MHD patients. Systemic inflammation not only increases protein degradation in the skeletal muscle, but it also suppresses protein synthesis, leading to an amplified net catabolism. When examining muscle tissue to identify potential therapeutic targets, we were able replicate data previously shown by others, implicating robust activation of protein catabolic signaling pathways in mouse models of advanced CKD. 


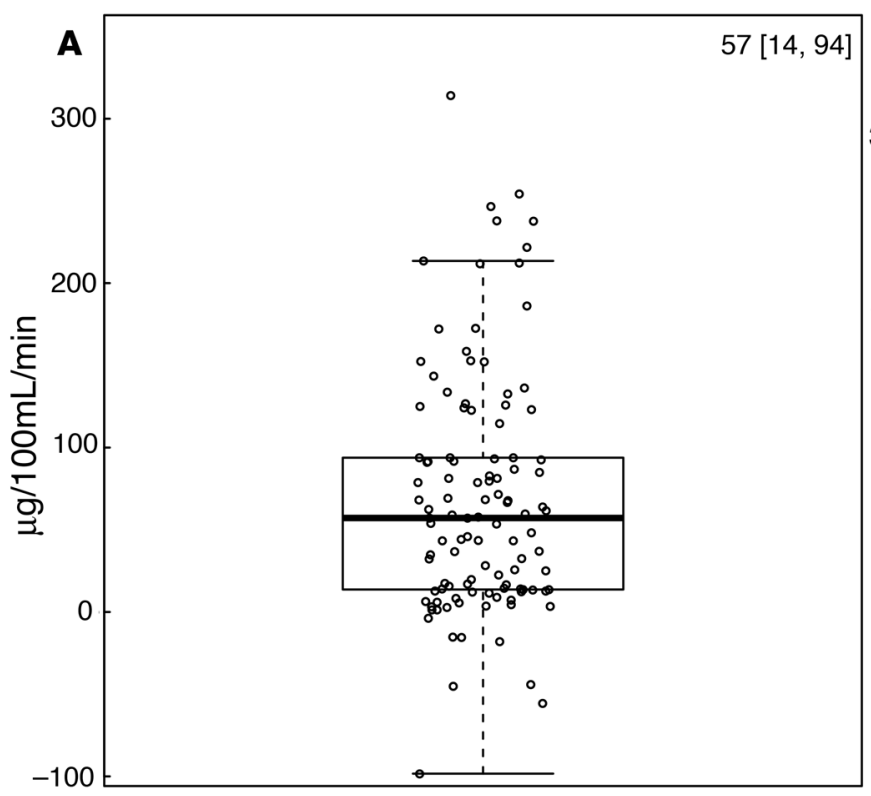

Forearm muscle protein synthesis

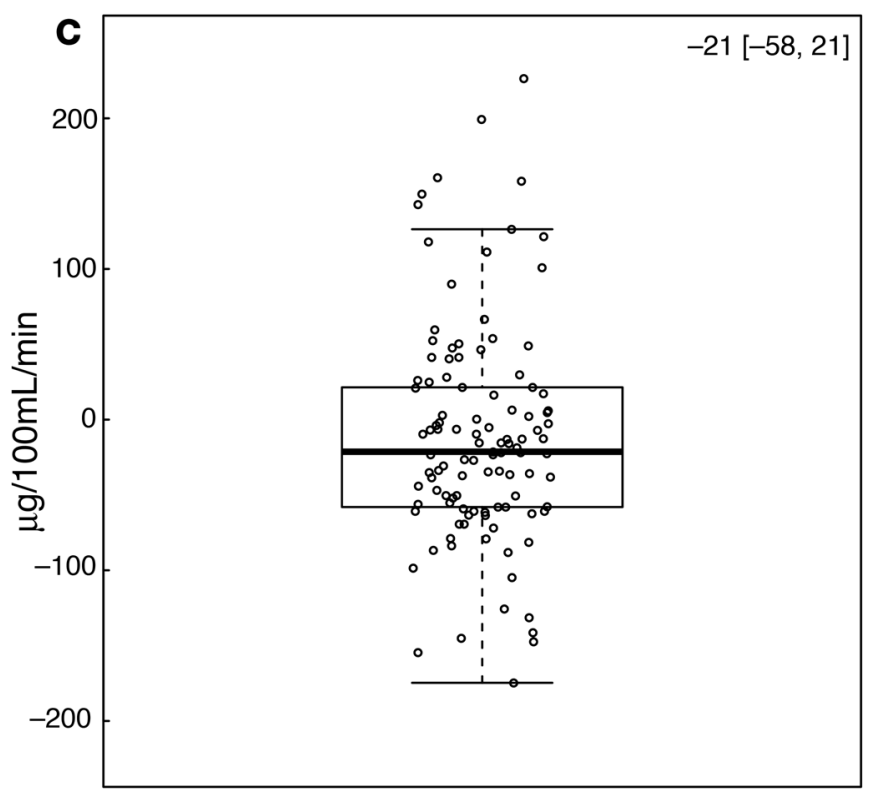

Forearm net muscle protein balance

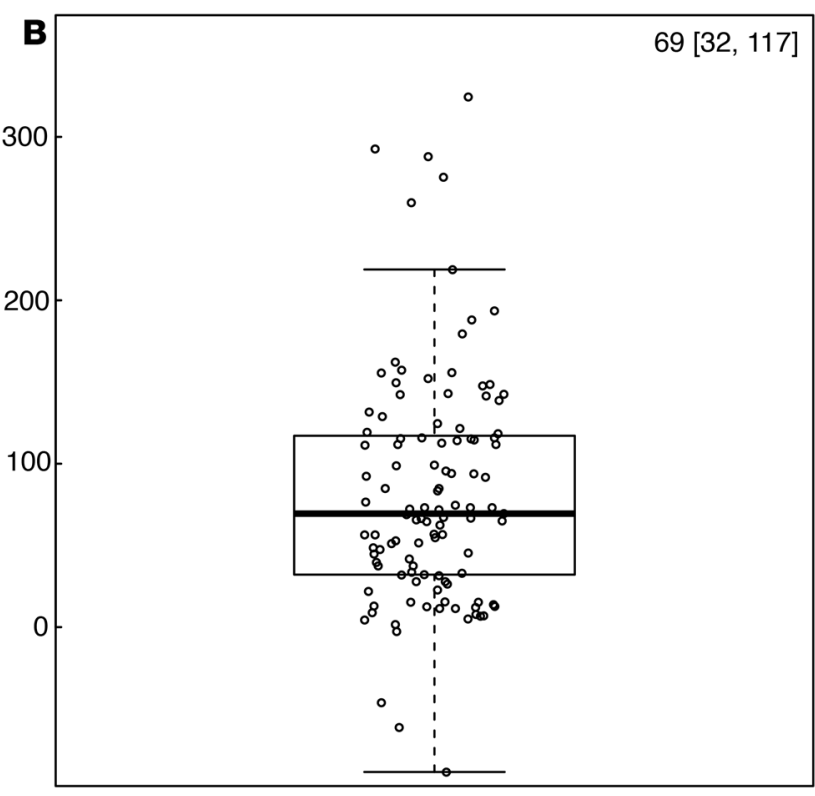

Forearm muscle protein breakdown
Figure 2. Forearm muscle protein turnover components for the study cohort. We retrospectively analyzed forearm skeletal muscle protein turnover components (i.e., skeletal muscle protein synthesis, breakdown, and net balance rates) in $129 \mathrm{MHD}$ patients. Forearm skeletal muscle protein synthesis (A) was lower compared with breakdown, resulting in a negative net skeletal muscle protein balance (C) as expected in fasting state. All data are presented as median (interquartile range).

The mortality rate in MHD patients is $18 \%-20 \%$, with more than $50 \%$ of patients dying within $2-5$ years following initiation of MHD (7). Markers of systemic inflammation and protein energy wasting are arguably the most common and robust predictors of adverse clinical outcomes in MHD patients, including mortality $(8,9)$. Systemic inflammation can be detected in more than $50 \%$ of MHD patients, and the prevalence of protein energy wasting ranges between $60 \%-70 \%$ globally in this patient population $(10,11)$. If, indeed, they are causally related and amelioration of one leads to improvements in the other, that could have important clinical implications. While both systemic inflammation and protein energy wasting are readily recognized as important comorbid conditions by practicing nephrologists, enthusiasm for measuring inflammatory markers has been dampened by a previous lack of effective therapies. Our data suggest that detection and management of systemic inflammation should be a vital component of care in maintenance dialysis patients. If validated by additional follow-up studies, a significant number of deaths and other adverse clinical events can be averted in MHD patients by this strategy. 

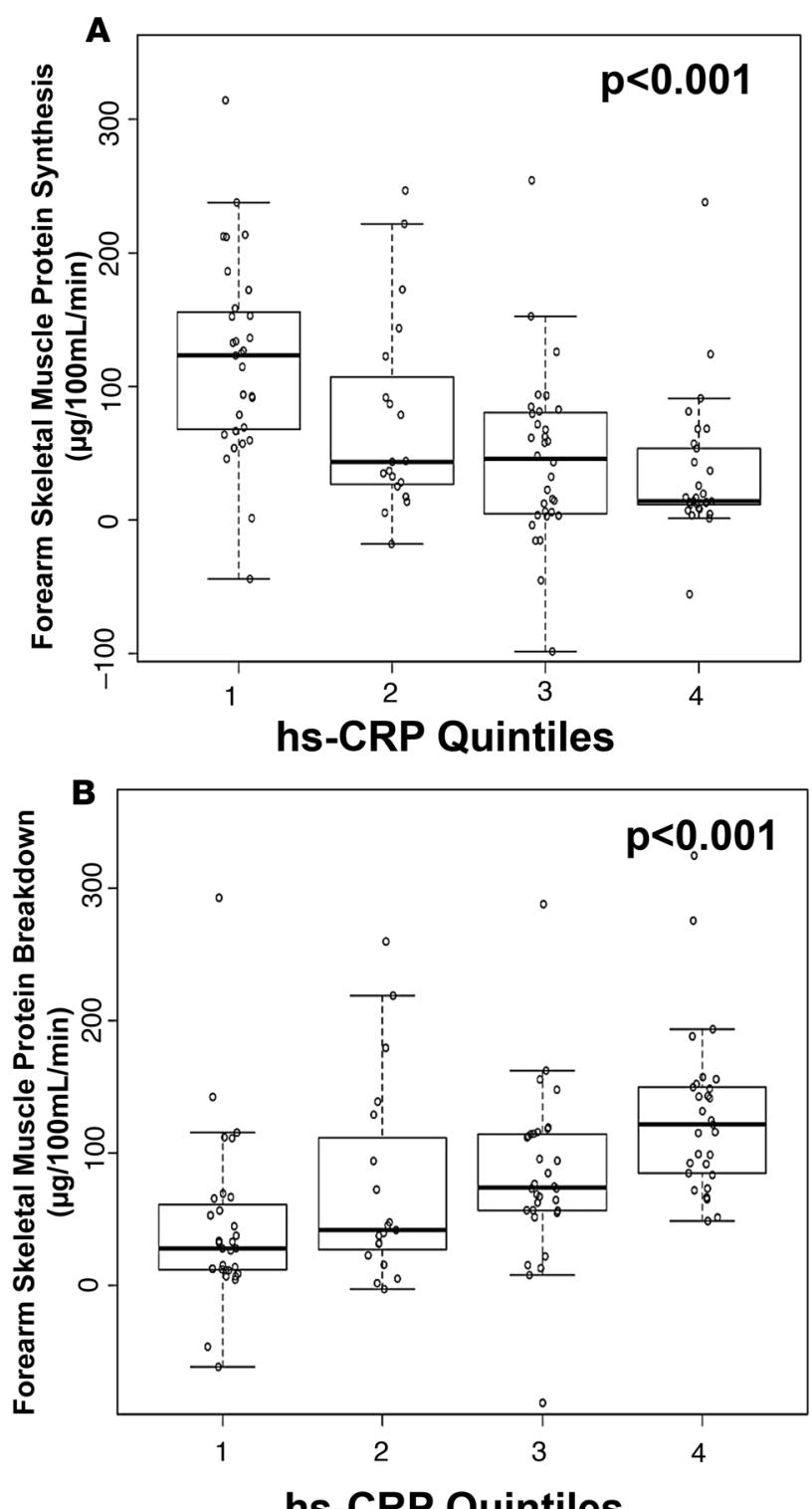

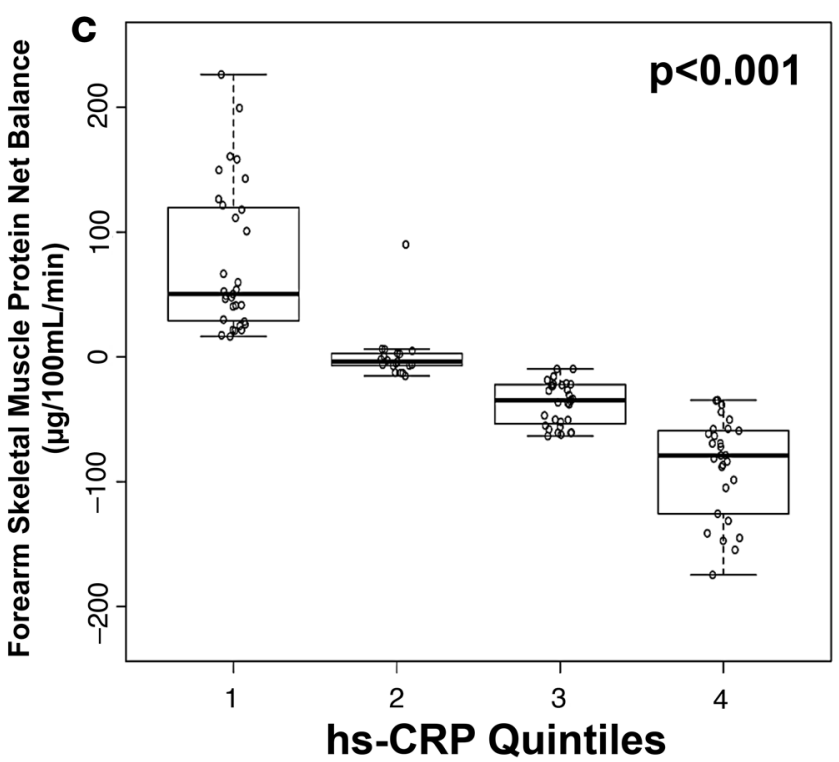

Figure 3. The rates of forearm muscle protein components according to hs-CRP concentrations grouped by quintiles among MHD patients. We examined protein turnover markers are presented as median (interquartile range) after categorizing patients into quartiles based on their hs-CRP values: quintile 1 , no inflammation $(n=32)$, 0.1-0.7 mg/l; quintile 2, medium inflammation $(n=33), 0.8-12.9 \mathrm{mg} / \mathrm{l}$; quintile 3 , high inflammation $(n=33), 13.0-33.2 \mathrm{mg} / \mathrm{l}$; and quintile 4 , severe inflammation $(n=32), 33.3-59.0 \mathrm{mg} / \mathrm{l}$. There were statistically significant associations between hs-CRP quintiles and forearm skeletal muscle protein synthesis (A), protein degradation (B), and net forearm skeletal muscle protein balance (C) $(P<0.001$ for all). The unadjusted comparisons of 4 groups defined by hs-CRP quintiles and various skeletal muscle and whole body protein turnover components were performed using the Kruskall-Wallis test, and the data are depicted as box plots.

The association between systemic inflammation and markers of nutrition has been reported in multiple epidemiological studies (12-14). There are also a small number of studies examining the effects of systemic and local inflammation on protein turnover in MHD patients, albeit this is limited due to very small sample size. Caglar et al. reported that fractional synthesis rates of albumin and fibrinogen, along with production of IL-6, increased during hemodialysis and even beyond 2 hours after the hemodialysis period, indicating that the hemodialysis procedure itself is an inflammatory trigger for MHD patients (1). In a pilot study, Raj et al. reported that there was a positive correlation between plasma IL-6 levels and fractional synthesis rates of skeletal muscle during hemodialysis and concluded that the organized increase in the fractional synthesis rates is related to triggered inflammation by hemodialysis (15). Similarly, Garibotto et al. showed that higher release of IL- 6 by the skeletal muscle leads to higher phenylalanine release 15 MHD patients (16). Our results extend these associative data, providing the most concrete evidence to our knowledge regarding the mechanism by which systemic inflammation leads to sarcopenia. The robustness of the statistical association between hs-CRP and net protein balance is potentially unique and unprecedented. Our data also indicate that systemic inflammation has dual adverse effects on skeletal muscle protein balance (i.e., simultaneously increasing protein catabolism and decreasing protein synthesis). Indeed, it is quite uncommon to see a specific biological process to simultaneously affect protein balance in this bidirectional manner. There is a physiological balance between protein synthesis and protein breakdown designed to compensate for 
Table 2. Forearm skeletal muscle protein turnover components over hs-CRP quintiles

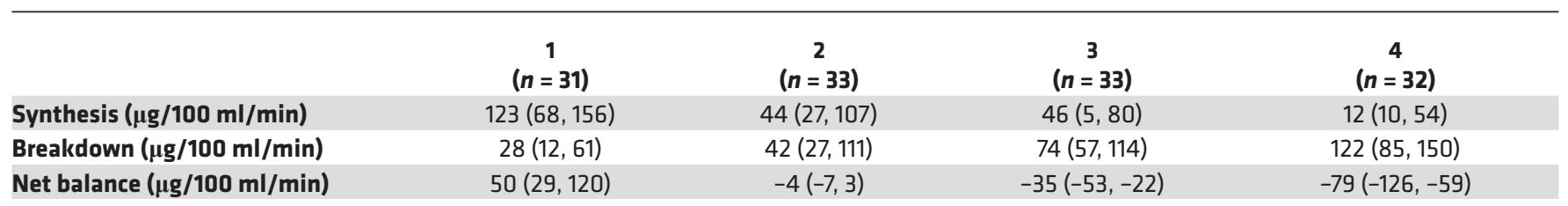

The group is categorized according to the quartiles: quartile 1 as normal, 0.1-0.7 mg/l; quartile 2 as medium, 0.8-12.9 mg/l; quartile 3 as high, 13.0-33.2 $\mathrm{mg} / \mathrm{l}$; and quartile 4 as severe, 33.3-59.0mg/l.

each other to maintain a net nitrogen balance, such that a decrease in protein breakdown is almost exclusively compensated for by a decrease in protein synthesis due to decreased substrate availability and vice versa. This observation can, to some extent, explain the relatively high impact of systemic inflammation on clinical outcomes and its robust association with markers of protein energy wasting in MHD patients.

To assess whether these significant associations between hs-CRP and muscle protein turnover components exist after adjusting by other potential determinants of muscle protein turnover markers such as age, sex, race, dialysis vintage, presence of insulin resistance, serum albumin levels, and FM, we performed multivariable linear regression analysis in 2 different models. In all analyses, hs-CRP levels were statistically significantly associated with all muscle protein turnover components. While most if not all of these variables are associated with poor nutrition state in MHD patients in epidemiological studies, we were not able to show any statistically significant associations for any of these variables in terms of net skeletal muscle protein balance.

$\mathrm{DM}$ is one of the most significant determinants of protein homeostasis. We have previously shown that presence of insulin resistance or overt DM is associated with worsened net skeletal muscle protein catabolism in MHD patients $(2,17)$. In this study, only a small percent of patients $(n=14)$ had overt DM, which did not allow us to examine whether there is an interaction between inflammation and DM in terms of the extent of skeletal muscle protein breakdown. On the other hand, we were able to show that the adverse effects of systemic inflammation are independent of presence or absence of insulin resistance or overt DM. Additional studies are necessary to understand how abnormalities in insulin signaling contribute to already recognized catabolic effects of systemic inflammation in MHD patients.

We also examined certain signaling pathways in the skeletal muscle tissue obtained from an established mouse model of CKD to provide further insight for potential intervention targets. One noticeable finding in these studies was that the catabolic signals are primarily activated in animals with significant concomitant inflammatory response. While these data do not necessarily cover the complete metabolic cascade leading to increased catabolism, they should be considered as suggestive of the significant impact of systemic inflammation on muscle tissue. Further experiments examining human muscle tissue should be contrasted to confirm these results, taking into account the biological heterogeneity observed in humans versus animal experiments.

This study has certain strengths. It is the largest cohort to our knowledge that examines the association between systemic inflammation and forearm and whole body protein homeostasis by using isotope tracer methodology in MHD patients. This remarkably large sample size $(n=129)$ allowed us to properly develop multivariable models, accounting for coexisting conditions that are known to influence protein homeostasis, which has never been employed to our knowledge, despite the well-known variability seen in physiological assessment of protein homeostasis in humans. Our cohort consists of mostly male and African American predominance. We believe that the nature of the study patients reflects the general MHD population in the US, which enables the generalizability of our findings to the broader MHD population. Furthermore, by using animal models, we were be able to evaluate the potential mechanistic pathways that might explain the association between inflammation and muscle protein turnover at the cellular level in an advanced CKD state.

The study has several limitations. While providing the largest cohort of its kind, the initial findings are associative by nature and do not prove a cause-and-effect relationship. We used hs-CRP as the sole marker of systemic inflammation, and we might observe a different relationship between other proinflammatory cytokines and protein turnover. Our additional analysis in a smaller cohort of subjects $(n=56)$ in whom IL-6 was measured, we were not able to show statistically significant association although the trends were in the same direction with hs-CRP analysis using the complete cohort (Supplemental Figure 

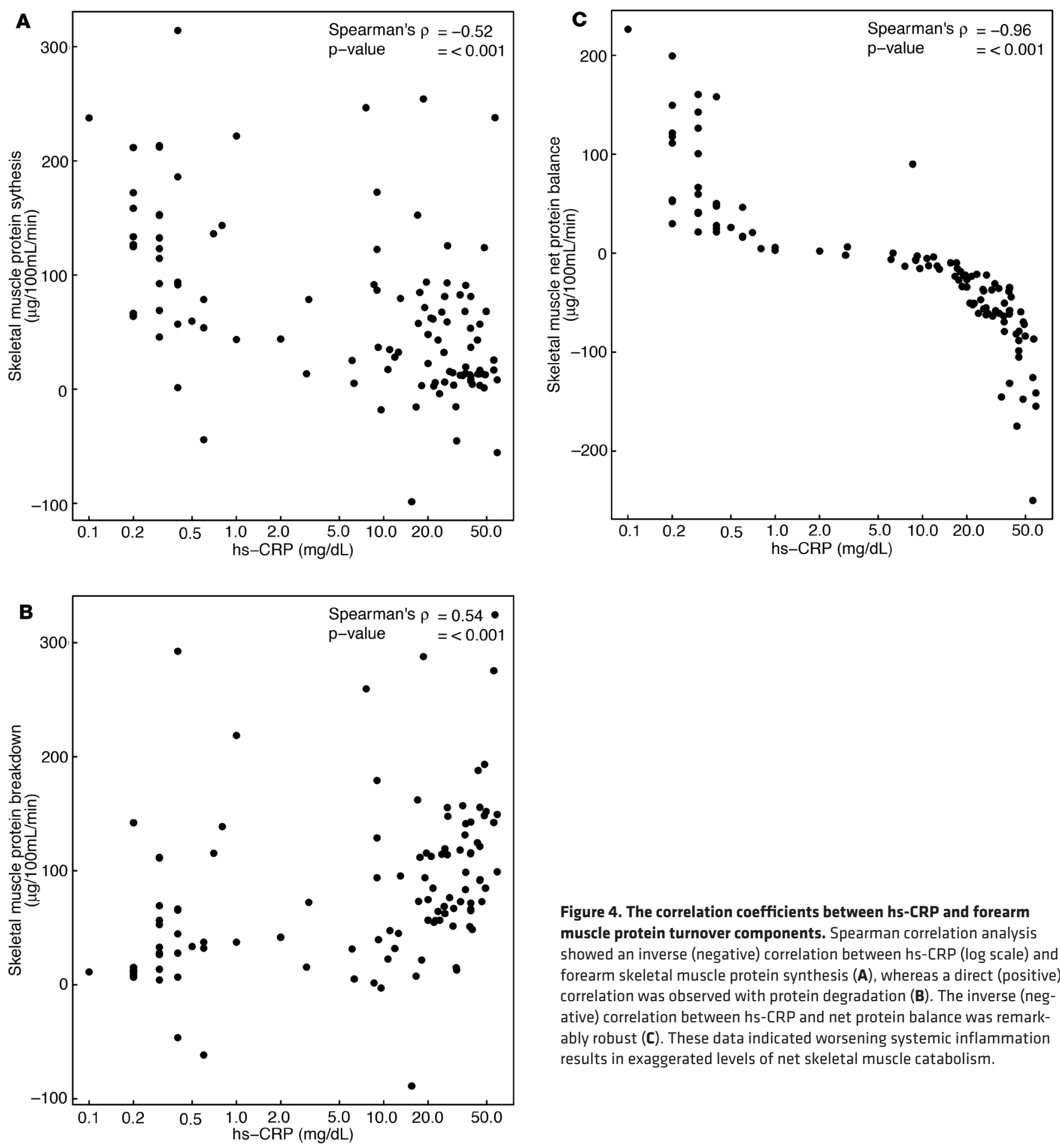

Figure 4. The correlation coefficients between hs-CRP and forearm muscle protein turnover components. Spearman correlation analysis showed an inverse (negative) correlation between hs-CRP (log scale) and forearm skeletal muscle protein synthesis (A), whereas a direct (positive) correlation was observed with protein degradation (B). The inverse (negative) correlation between hs-CRP and net protein balance was remarkably robust (C). These data indicated worsening systemic inflammation results in exaggerated levels of net skeletal muscle catabolism.

4). This discrepancy could be due to a number of reasons, including but not limited to different effects of hs-CRP versus IL-6 in regards to skeletal muscle protein metabolism or a lack of IL-6 inducing a significant catabolic effect that could be teased out by physiological studies applied in this study. The consistent trend with hs-CRP without statistical significance also suggests that this could be related to inadequate sample size in regards to IL-6 analysis. MHD patients suffer from significant comorbidities, such as heart failure, that might lead sarcopenia. While we did not have exclusion criterion regarding presence of heart failure, most if not all of the study patients were free of acute decompensated illnesses. Nevertheless, these comorbidities might have influenced our results. Finally, the muscle tissue analysis should take into account the 
Table 3. Multivariable regression models for determinants of skeletal muscle protein turnover components

\begin{tabular}{|c|c|c|c|c|c|c|}
\hline \multicolumn{7}{|l|}{ MODEL 1} \\
\hline & Partial effect ${ }^{A}(95 \% \mathrm{Cl})$ & $P^{B}$ & Partial effect $(95 \% \mathrm{Cl})$ & $\mathbf{p}$ & Partial effect $(95 \% \mathrm{CI})$ & $\boldsymbol{P}$ \\
\hline Race (AA) & $-15(-65,34)$ & 0.32 & $12(-35,58)$ & 0.53 & $-27(-57,3)$ & 0.15 \\
\hline Sex (Female) & $-22(-64,19)$ & 0.29 & $-37(-77,2)$ & 0.06 & $15(-10,40)$ & 0.23 \\
\hline Dialysis vintage & $4(-24,33)$ & 0.77 & $-4(-31,22)$ & 0.74 & $9(-8,26)$ & 0.31 \\
\hline Serum albumin & $-2(-30,25)$ & 0.86 & $-11(-37,14)$ & 0.38 & $9(-7,25)$ & 0.28 \\
\hline Fat mass & $-11(-35,14)$ & 0.40 & $-1(-25,22)$ & 0.91 & $-9(-24,6)$ & 0.22 \\
\hline hs-CRP & $-65(-119,-11)$ & $<0.001$ & $40(-10,91)$ & $<0.001$ & $-105(-137,-74)$ & $<0.001$ \\
\hline \multicolumn{7}{|l|}{ MODEL 2} \\
\hline Age & $-2(-36,32)$ & 0.91 & $-8(-39,23)$ & 0.61 & $6(-15,27)$ & 0.57 \\
\hline Prealbumin & $15(-12,42)$ & 0.28 & $5(-19,30)$ & 0.65 & $9(-8,26)$ & 0.28 \\
\hline Serum albumin & $6(-23,34)$ & 0.68 & $-4(-30,22)$ & 0.78 & $10(-8,28)$ & 0.28 \\
\hline Fat mass & $-2(-29,25)$ & 0.89 & $4(-20,29)$ & 0.72 & $-6(-23,11)$ & 0.47 \\
\hline hs-CRP (log) & $-38(-94,18)$ & $<0.001$ & $64(13,115)$ & $<0.001$ & $-103(-138,-68)$ & $<0.001$ \\
\hline \multicolumn{7}{|c|}{$\begin{array}{l}\text { APartial effect for a continuous variable is the estimated mean difference in the outcome between an observation at the } 75 \text { th and } 25 \text { th percentile of } \\
\text { the continuous variable. For example, a partial effect of age being equal to }-15 \text { for protein synthesis indicates that, holding all other variables constant, } \\
\text { a participant with an age in the } 75 \text { th percentile is (estimated to be) } 15 \text { units less than a participant with an age in the } 25 \text { th percentile. For a categorical } \\
\text { variable, the partial effect is the mean difference in outcome between the indicated category and the reference category. }{ }^{B} P \text { values refer to } F \text { tests of } \\
\text { overall covariate significance. }\end{array}$} \\
\hline
\end{tabular}

multiple comorbidities that these patients suffer when extrapolating to these results obtained from animal models to humans with kidney disease. It is of note that we are unable to provide further mechanistic information related to role of $\beta 1$ integrin, which can apparently regulate muscle turnover directly, circumventing a role for inflammation in rodent muscle wasting (18).

In this study, we found that systemic inflammation, as assessed by hs-CRP, is a strong and independent determinant of skeletal muscle protein homeostasis in MHD patients. Our results provide strong rationale for further studies using anticytokine therapies in patients with underlying systemic inflammation, while more targeted therapies in humans need further investigation in the setting of advanced kidney disease.

\section{Methods}

\section{Study population}

We conducted a retrospective analysis of $129 \mathrm{MHD}$ patients who had formerly participated in a variety of metabolic studies at VUMC or the VA-THS between July 1998 and March 2011 (Supplemental Table 4). All patients signed written informed consent prior to participating in the study. Inclusion criteria included those aged 18 years and older who were on MHD for more than 3 months and who were delivered an adequate dose of dialysis (single-pool $\mathrm{Kt} / \mathrm{V}>1.2$ ) on a thrice-weekly dialysis program using biocompatible hemodialysis membranes. Exclusion criteria included pregnancy, patients with severe unstable underlying disease who had vasculitis or liver disease, and those hospitalized within 1 month prior to enrollment into the study.

Demographical and clinical data were obtained including age, sex, ethnicity, BMI, and body composition. BMI was calculated as the weight in kilograms divided by height in square meters. The dialysis vintage was defined as the duration of time between the first day of the dialysis therapy and the day the blood draws were performed. 

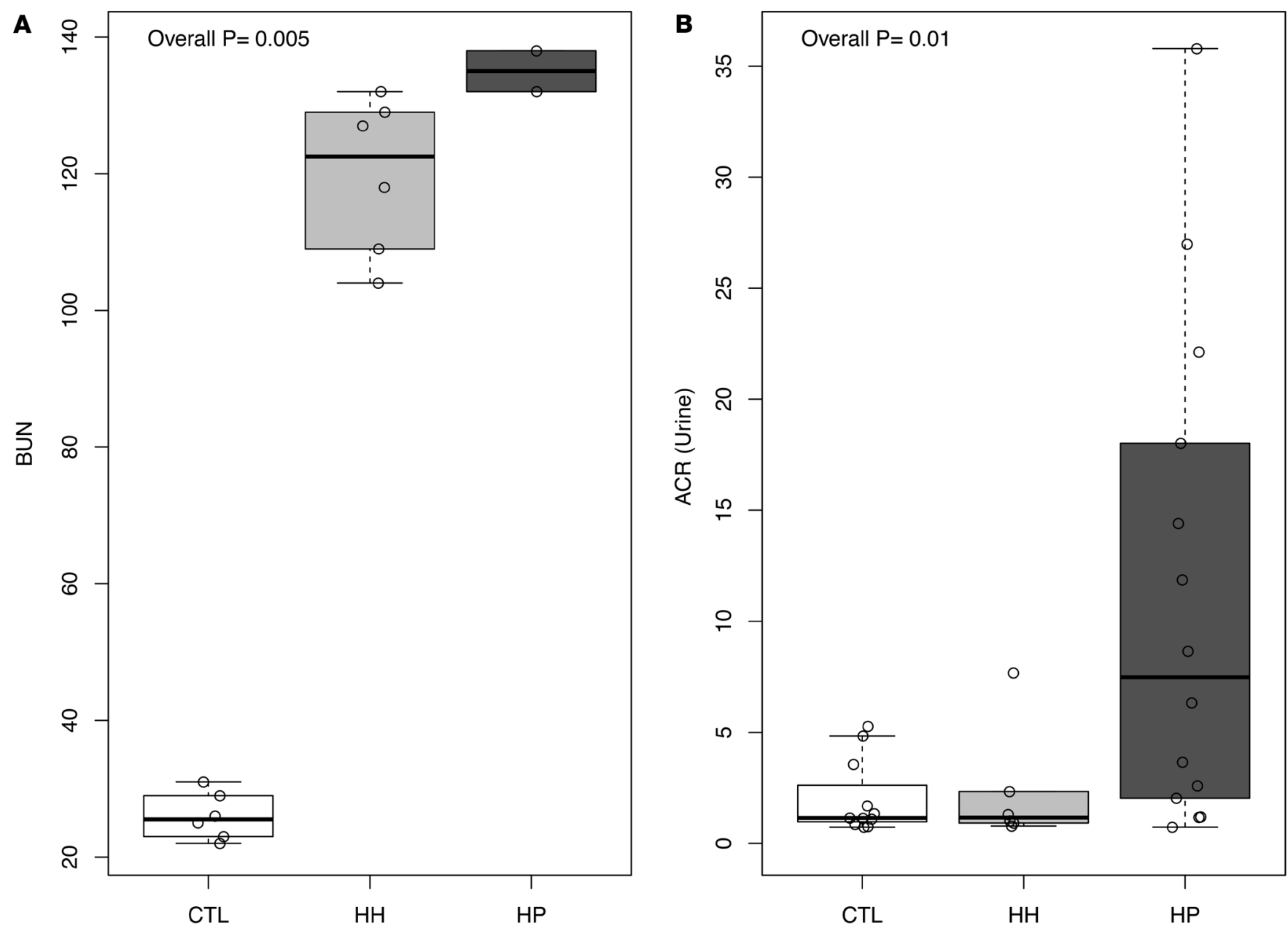

Figure 5. Albumin/creatinine ratio and BUN levels of WT mice, HoxB7 Cre mice (Hom-Hox) and mice lacking $\beta 1$ integrin in the podocytes (Hom-Pod). Albumin/creatinine ratio and BUN levels are presented as mean \pm SEM. $\beta 1 \mathrm{Hom}$-Pod mice were smaller and had paler kidneys and displayed skeletal muscle atrophy along with less weight compared with WT mice. $\beta 1 \mathrm{Hom}$-Hox mice presented with same characteristics (refs. 5 and 6 ). There was a statistically significantly difference between Hom-Pod mice versus WT and no difference between WT versus Hom-Hox mice for albumin/creatinine ratio (A). BUN concentrations were numerically higher in Hom-Pod and Hom-Hox mice compared with WT (B).

\section{Measurement of body composition}

Assessment of body composition was performed by dual energy x-ray absorptiometry (DEXA), which offers a noninvasive 3-compartment evaluation that quantifies FM, lean body mass (LBM), and bone mineral content with minimal radiation exposure. All DEXA measurements were performed on a nondialysis day before metabolic study protocol, using a Lunar Prodigy iDEXA machine, v.11.40.004 (software versions 1998 to 2011, General Electric)

\section{Assessment of insulin resistance}

Clinical diagnosis of DM was made according to the ADA clinical practice guidelines or presence of history of DM in medical records. In addition to monitor diabetes status, HOMA-IR (insulin $[\mu \mathrm{U} / \mathrm{ml}] \times$ glucose $[\mathrm{mg} /$ dl $] / 405$ ) and HOMA-AD (insulin $[\mu \mathrm{U} / \mathrm{mL}] \times$ glucose $(\mathrm{mg} / \mathrm{dl}) / 405 \times$ adiponectin $[\mathrm{mg} / \mathrm{ml}]$ ) were calculated. In the general population, previously determined reference values for HOMA-IR is HOMA-IR > $2.6(19,20)$.

\section{Laboratory analysis}

All blood sampling was performed at the General Clinical Research Center (GCRC) and analyzed at VUMC central laboratories. After blood draw was performed, samples were transported on ice and centrifuged at $6,441 \mathrm{~g}$ for 15 minutes before kept frozen at $-80^{\circ} \mathrm{C}$. Plasma fasting glucose concentrations were 
A

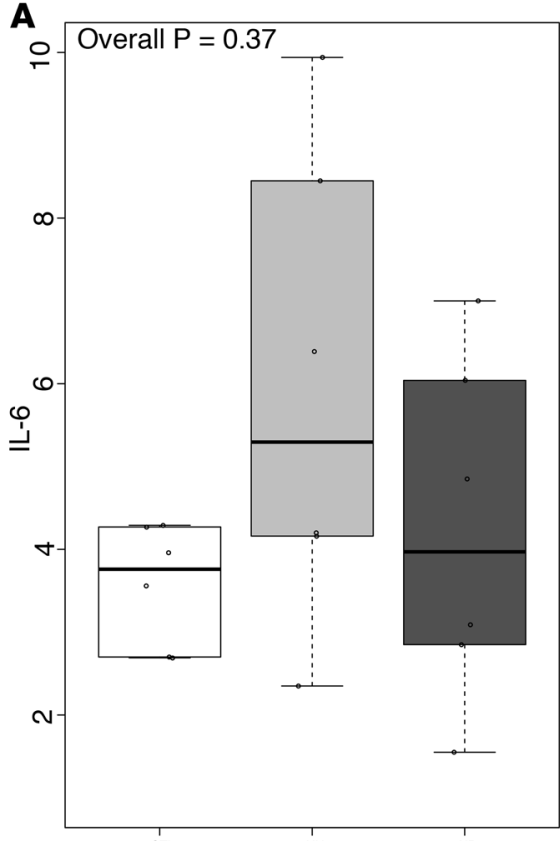

CTL

B

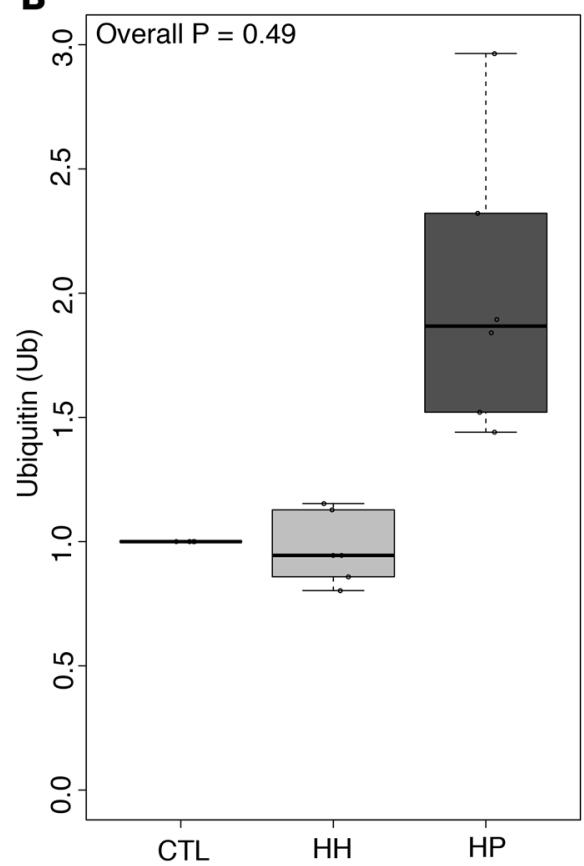

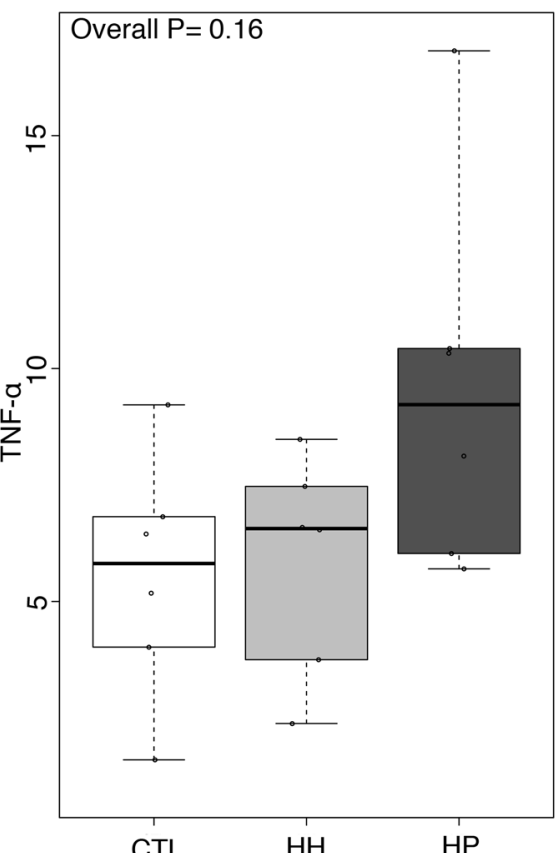

CTL

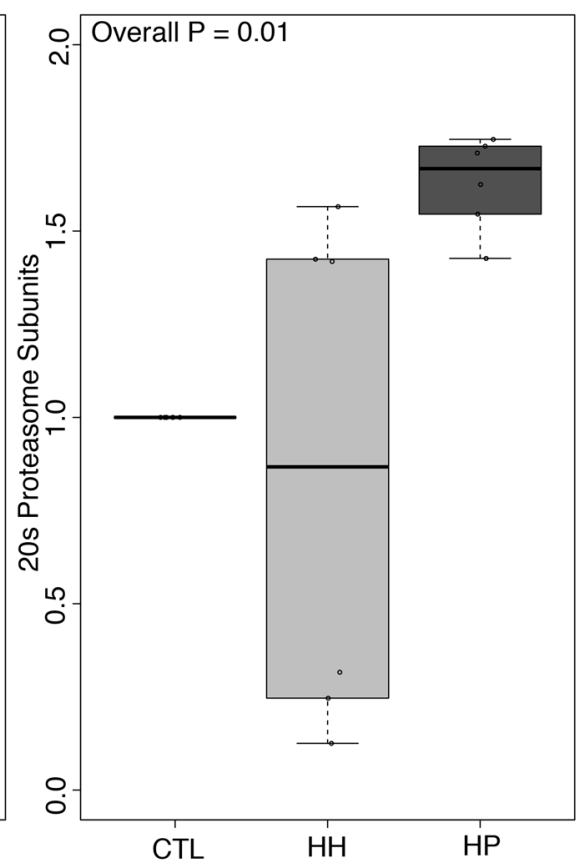

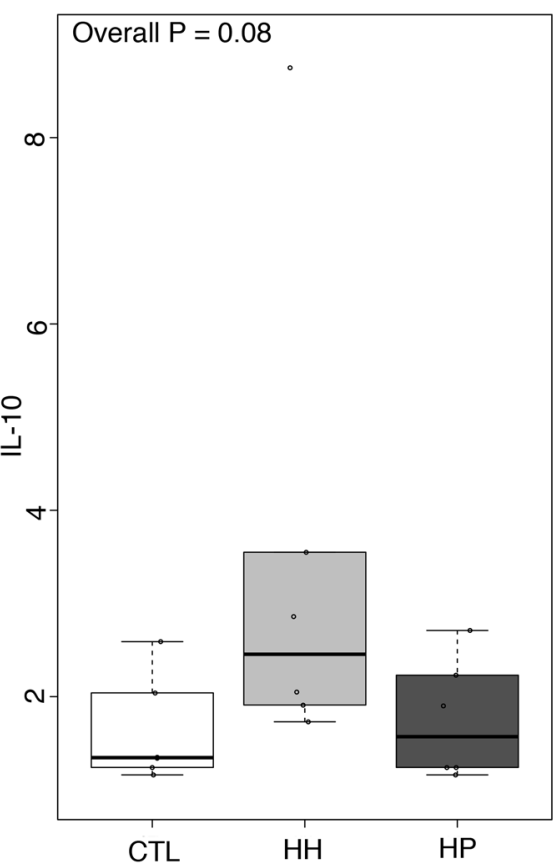

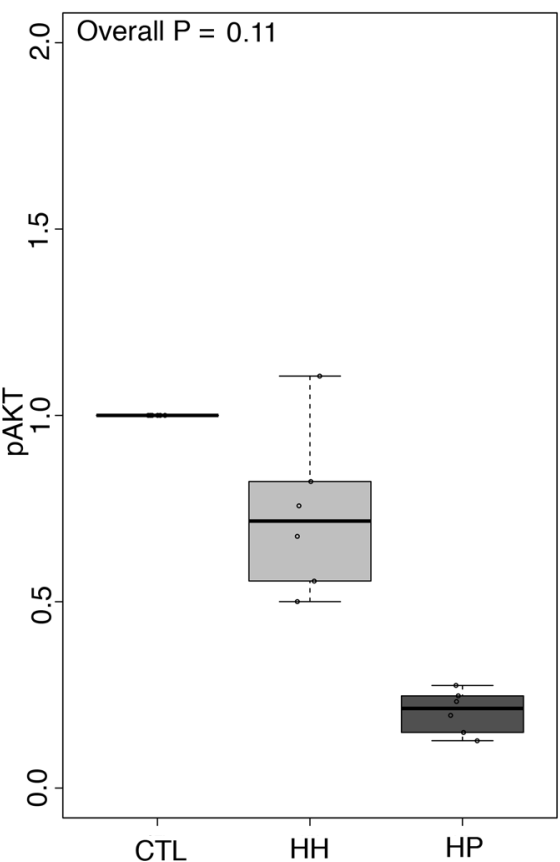

Figure 6. The analysis of cytokines and tissue markers of protein homeostasis in CKD mice and controls. Serum cytokines (A), relative protein expression by immunoblot (B) and relative mRNA expression by real-time PCR ( $C$ and $\mathbf{D})$ are depicted for WT $(n=6)$, HoxB7 Cre mice (Hom-Hox, $n=6)$ and mice lacking $\beta 1$ integrin in the podocytes (Hom-Pod, $n=6$ ). Parameters are presented as mean \pm SEM. There were numerical differences in serum concentrations of serum IL-6, IL-10, and TNF- $\alpha$ between groups although none of these differences reached statistical significance (A). There was an overall statistically significant difference between groups when comparing $20 \mathrm{~S}$ proteasome subunits $(P=0.01)$ but not with Ubiquitin (Ub) conjugates and pAKT by immunoblotting $(P=0.49$ and $P=0.11$, respectively). In group comparisons (B), Ub-conjugates, 205 proteasome subunits, and pAKT were highly statistically significantly elevated in Hom-Pod mice compared with WT or Hom-Hox mice $(P<0.003$ for all). There were no statistically significant differences in Ub, $20 \mathrm{~S}$ proteasome subunits, and pATK when comparing Hom-Hox mice versus WT mice $(P>0.0125$ for all).

analyzed by using the glucose oxidase method (Glucose analyzer 2; Beckman Coulter). Concentrations of serum albumin, prealbumin, and bicarbonate were measured using standard methods at VUMC central laboratories. High-sensitivity C-reactive protein concentrations were measured by high-sensitivity particle enhanced turbidometric Unicel Dxl Immunoassay system (Beckman Coulter). Plasma insulin levels were 

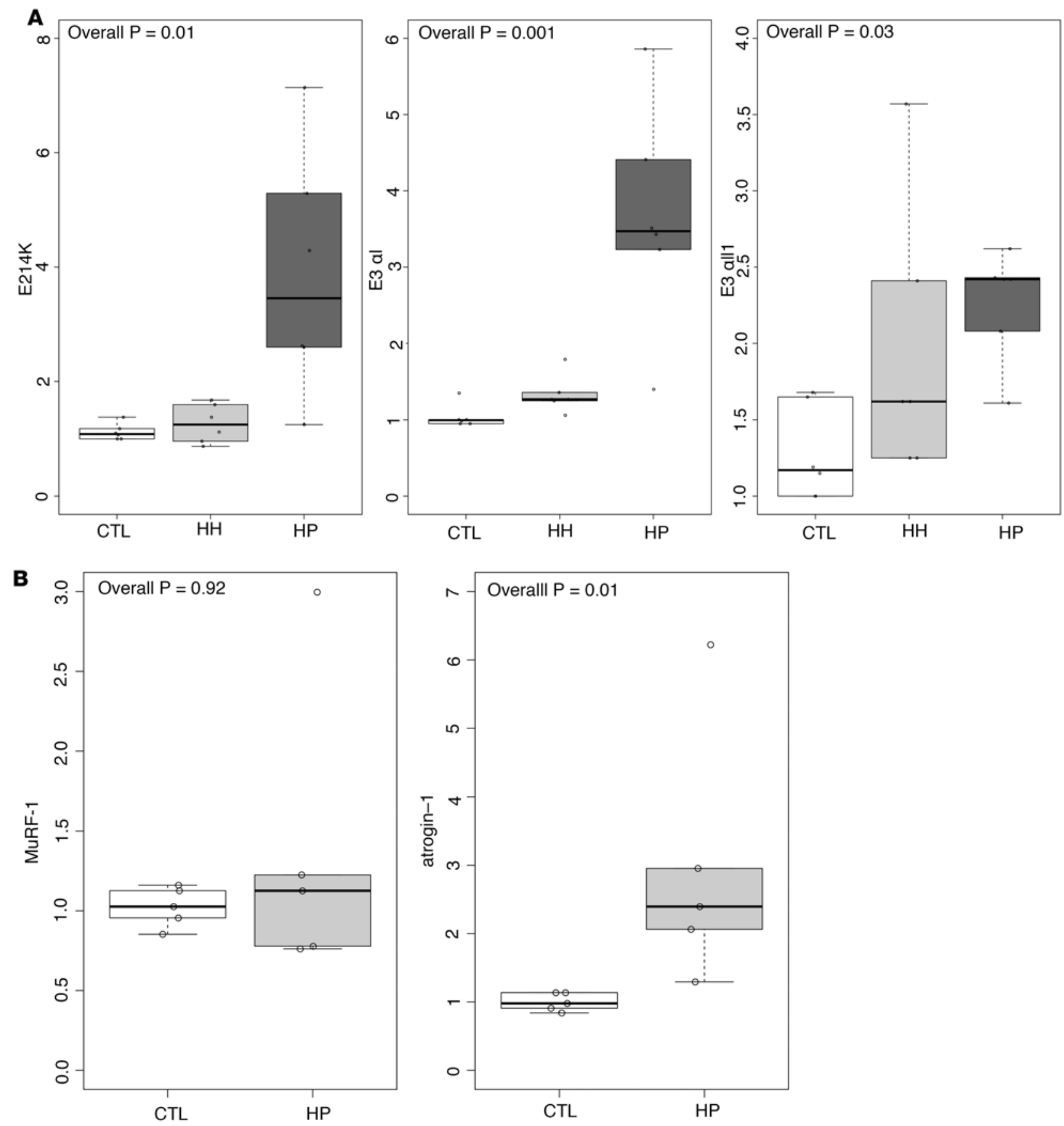

Figure 7. Further analysis of cytokines and tissue markers of protein homeostasis in CKD mice and controls. There were overall statistically significant differences for mRNA expression of E214K, E3 $\alpha$ l, and E3 $\alpha$ ll1 by real-time PCR between groups ( $P<0.05$ for all) (A). In group comparisons, E214k, E3 $\alpha$ l, and E3all expressions were statistically significantly higher in Hom-Pod mice compared with WT mice $(P<0.003$ for all) (A). E214K and E3 $\alpha$ l were also statistically significantly higher in Hom-Pod mice versus Hom-Hox mice ( $P<0.01$ for both). E3all1 was not different between Hom-Pod versus Hom-Hox mice. There were no statistically significant differences in when comparing E214K, E3 $\alpha$ l, and E3 $\alpha$ ll1in Hom-Hox mice versus WT mice (P>0.0125 for all) (A). MuRF-1 and atrogin-1 expressions were numerically higher in Hom-Pod mice compared with WT mice, with atrohgin-1 reaching statistical significance only (B).

measured by a double-antibody radioimmunoassay (MilliporeSigma). Adiponectin and leptin were measured using the MILLIPEXMAP Human Serum Adiponectin Panel A kit (MilliporeSigma).

\section{Metabolic study design}

The patients were admitted to GCRC the day before the study and received a meal from GCRC bionutrition services after admission; they remained in a fasting state after that. The last meal was given at least 10 hours 
prior to the initiation of the study for all patients. All metabolic studies were performed at least 24 hours after the most recent hemodialysis procedure. A schematic diagram of the metabolic study protocol that was used for all studies is depicted in Figure 1. A fistula needle (Medisystems) was placed at both venous and arterial sides of the arteriovenous access. After obtaining venous blood samples, venous side used for isotope infusion and arterial side was used to obtain arterial blood samples. Another i.v. catheter was placed with retrograde manner in a deep vein of the contralateral arm to obtain forearm muscle bed sampling. After receiving a bolus injection of $\mathrm{NaH}^{13} \mathrm{CO}_{3}(0.12 \mathrm{mg} / \mathrm{kg}), \mathrm{L}-\left(1-{ }^{13} \mathrm{C}\right)$ leucine $(7.2 \mu \mathrm{mol} / \mathrm{kg})$, and L-(ring- $\left.{ }^{2} \mathrm{H}_{5}\right)$ phenylalanine $(7.2 \mu \mathrm{mol} / \mathrm{kg})$, a continuous infusion of leucine $(0.12 \mu \mathrm{mol} / \mathrm{kg} / \mathrm{min})$ and phenylalanine $(0.12 \mu \mathrm{mol} / \mathrm{kg} /$ $\mathrm{min}$ ) isotopes was started and continued throughout the study. Each metabolic study consisted of a 2-hour equilibration phase followed by a 120-minute sampling period. Simultaneously with each blood sampling, breath samples were collected from the subjects via Douglas bag with duplicate $20-\mathrm{ml}$ samples placed into nonsiliconized glass vacutainer tubes for measurement of breath ${ }^{13} \mathrm{CO}_{2}$ enrichment. Forearm blood flow was estimated using capacitance plethysmography (Model 2560 with URI/CP software version 3.0) during the equilibration phase. The technique has been explained previously (2). Energy expenditure and respiratory quotient were also determined by indirect calorimetry using metabolic cart (Sensormedics 2900) (2). Once the study was completed, patients received meals at the GCRC and were discharged.

\section{Protein turnover calculations}

Forearm skeletal muscle turnover. Net skeletal muscle balance (synthesis breakdown) was determined by dilution and enrichment of phenylalanine across the forearm, as described by Gelfand and Barrett (21). Rate of appearance $(\mathrm{Ra})$ of unlabeled phenylalanine reflects muscle protein breakdown, whereas the rate of disappearance (Rd) of labeled phenylalanine estimates muscle protein synthesis (21). Phenylalanine Rd was calculated by multiplying the fractional extraction of the labeled phenylalanine by the arterial phenylalanine concentration and was normalized to forearm blood flow measured by plethysmography. Net phenylalanine Ra was calculated by subtracting the net arteriovenous AV balance of phenylalanine across the extremity from the phenylalanine $\mathrm{Rd}$ $(21,22)$. Rates of forearm skeletal muscle protein breakdown and synthesis were determined from phenylalanine $\mathrm{Rd}$ and $\mathrm{Ra}$, assuming that $3.8 \%$ of skeletal muscle protein is composed of phenylalanine.

Whole body protein turnover. The steady-state rates of total whole body leucine Ra were calculated by dividing the $\left({ }^{13} \mathrm{C}\right)$ leucine infusion rate by the plasma $\left({ }^{13} \mathrm{C}\right) \mathrm{KIC}$ enrichment $(22)$. Steady state conditions for KIC and $\mathrm{CO}_{2}$ enrichments were achieved, as evidenced by slopes within each phase not significantly different than 0 . Breath ${ }^{13} \mathrm{CO}_{2}$ was determined by multiplying the total $\mathrm{CO}_{2}$ production rate by the breath ${ }^{13} \mathrm{CO}_{2}$ enrichment. The rate of whole body leucine oxidation was calculated by dividing breath ${ }^{13} \mathrm{CO}_{2}$ production by 0.8 (correction factor for the retention of ${ }^{13} \mathrm{CO}_{2}$ in the bicarbonate pool) (23) and by the plasma KIC enrichment. The leucine $\mathrm{Rd}$, an estimate of whole body protein synthesis, was determined indirectly by subtracting leucine oxidation from total leucine $\mathrm{Rd}$. Rates of whole body protein breakdown, amino acid oxidation, and protein synthesis were calculated from the endogenous leucine $\mathrm{Ra}$, the leucine oxidation rate, and the nonoxidative leucine $\mathrm{Rd}$, respectively, assuming that $7.8 \%$ of whole body protein is composed of leucine (24).

\section{Methods and design of animal experiments}

Mice. In this study, we used 2 different integrin $\beta 1$ gene $\mathrm{KO}$ mice models $(5,6)$. Briefly, integrin $\beta 1^{\text {flox/flox }}$ mice, in which a promoterless lacZ reporter gene was introduced after the downstream loxP site, were crossed with the podocin-Cre mice (Hom-Pod) or HoxB7 Cre mice $(25,26)$. Age-matched littermates homozygous for the floxed integrin $\beta 1$ gene, but lacking Cre $\left(\beta 1^{\text {flox/flox }}\right.$ mice), were used as controls. The mice were sacrificed by cervical dislocation.

Cytokines Analysis. Serum IL-1 $\beta$, IL-6, IL-10, and TNF- $\alpha$ was measured by cytometric bead array (CBA) (BD Biosciences). CBAs were purchased from Becton Dickinson, and the measurements were performed according to the manufacturer's instructions. In brief, serum samples were thawed in a $37^{\circ} \mathrm{C}$ water bath, and $50 \mathrm{ml}$ of the serum sample in triplicate or $50 \mathrm{ml}$ of a cytokine standard mixture was added to a mixture of $50 \mathrm{ml}$ each of capture antibody and phycoerythrin (PE) detection reagent. The resulting $150 \mathrm{ml}$ mixture was incubated for 3 hours at room temperature and washed to remove unbound detector antibody-PE reagent before data acquisition using flow cytometry.

The intra- and interassay imprecisions of the CBA for all 4 cytokines were previously evaluated by BD Cytometric Bead Array Human Inflammatory Cytokines Kit. The variation of triplicate values in the present study (expressed as coefficients of variation) was $6.0 \%$ for TNF- $\alpha, 6.6 \%$ for IL-1, $6.4 \%$ for IL-6, and 
$6.2 \%$ for IL-10. The detection limits were $1.7 \mathrm{pg} / \mathrm{ml}$ for TNF- $\alpha, 1.9 \mathrm{pg} / \mathrm{ml}$ for IL-1, $1.3 \mathrm{pg} / \mathrm{ml}$ for IL-6, and $2.7 \mathrm{pg} / \mathrm{ml}$ for IL-10. The statistical analyses were calculated on the assumption that every value below the detection limit was $0.1 \mathrm{pg} / \mathrm{ml}$ less than the limiting value for each cytokine.

$m R N A$ analysis. Total RNA was isolated from muscle tissues using the TRIzol (Invitrogen) reagent. Following the manufacturer's instructions, cDNA was synthesized using Invitrogen SuperScript first-strand synthesis kit. To investigate the mRNA expression of cytokines, ubiquitin $\mathrm{C}(\mathrm{Ubc})$, activating and conjugating enzymes, and ubiquitin protein ligase in ubiquitin-proteasome pathway, real-time PCR (MyiQ Single-Color Real-Time PCR Detection System, Bio-Rad) was performed using SYBR Green Supermix (Bio-Rad). Briefly, $12.5 \mu 1$ of SYBR Green Supermix, $0.5 \mu 1$ of primer 5', $0.5 \mu 1$ of primer 3', $5 \mu 1$ of cDNA, and $6.5 \mu \mathrm{l}$ of distilled water (DNase and RNase free) reached $25 \mu 1$ of the final reaction volume. All primers were designed using the primer design software Primer3 according to the published sequences (GenBank). The primers were selected from areas unique to each gene to rule out coamplification of other transcripts during PCR. PCR was performed using an initial denaturation for 3 minutes at $95^{\circ} \mathrm{C}$, followed by 40 cycles of denaturation for 5 seconds at $95^{\circ} \mathrm{C}$, annealing for 20 seconds at $60^{\circ} \mathrm{C}$, and extension for 40 seconds at $72^{\circ} \mathrm{C}$. Acquired data were analyzed by Gene Expression Macro software version 1.1 (version 1.1; Bio-Rad). All PCR assays were performed in duplicate, and results are represented by the mean values. The relative amount of mRNA, normalized to a control GAPDH, was calculated by $2^{-\Delta \Delta C T}$. Quantitative PCR results were quantified and expressed as percentage change in copy numbers relative to the normal group.

Tissue handling and immunoblot. Muscle tissues were collected from mice legs, chopped to small pieces on ice, and then homogenized in $4 \mathrm{ml}$ of ice-cold buffer A (5 ml lysis solution $\mathrm{PH} 7.3,500 \mu \mathrm{L}$ Triton [10\%], $5 \mu 1$ Tween 20, $50 \mu 1$ sodium vanadate [100 mM], $50 \mu 1 \mathrm{NaF}$ [100 mM], and 1 tablet EDTA-free Preasnase Inhibitor [Roche] per $10 \mathrm{ml}$ buffer). Homogenates were centrifuged for 10 minutes $\left(1,500 \mathrm{~g}, 4^{\circ} \mathrm{C}\right)$ to pellet myofibrillar proteins, which were then washed 3 times in Buffer A containing 1\% Triton X-100. Myofibrillar proteins were then suspended in $8 \mathrm{M}$ urea/50 mM Tris/ $\mathrm{HCl}, \mathrm{pH} 7.5$. Supernatants from the $1,500 \mathrm{~g}$ spin were centrifuged for 20 minutes $\left(20,000 \mathrm{~g}, 4^{\circ} \mathrm{C}\right)$. These supernatants contained soluble proteins, and protein concentration was determined using the Bio-Rad Protein assay.

Proteins were pretreated by $2 \% \beta$-Mercaptoethanol and $4 \times$ NuPAGE Loading Buffer (Invitrogen) at $98^{\circ} \mathrm{C}$ for 10 minutes, and they were separated on a $10 \%$ SDS-polyacrylamide separating gel and $4 \%$ SDS-polyacrylamide stacking gel. Proteins $(40 \mu \mathrm{g})$ were loaded in each line, along with a Prestained SDSPAGE Standard (Bio-Rad). Gels were run for 2 hours at room temperature with the power supply set at $80 \mathrm{~V}$; then, stained proteins were transferred to nitrocellulose overnight, on ice, at $25 \mathrm{~V}$. The nitrocellulose membranes were blocked with $5 \%$ milk or 3\% BVA in Tris-buffered saline with $0.1 \%$ Tween (TTBS; 500 $\mathrm{mM} \mathrm{NaCl}, 20 \mathrm{mM}$ Tris-HCl, pH 7.5 and $0.1 \%$ Tween) for 1 hour. Membranes were immunoblotted in primary antibodies, p-AKT/AKT (Santa Cruz Biotechnology Inc.), Ubc (Novus Biologicals), and proteasome 20S (Enzo Life Sciences) overnight at $4^{\circ} \mathrm{C}$ (1: 2,000 dilution) and subsequently in secondary antibodies for 1 hour, which were diluted 1:2,500 in TTBS. Specific bands were visualized by chemiluminescence (ECL reagent, Amersham Bioscience). Specific proteins in the spot blot assay were estimated by Scion Image Software. See complete unedited blots in the supplemental material.

\section{Statistics}

The demographic, clinical, and laboratory characteristics were tabulated for all study participants. For continuous variables, we reported the median and interquartile range or the mean and SD; for categorical variables, we reported counts and percentages. The unadjusted comparisons of 4 groups defined by hs-CRP quintiles and various skeletal muscle and whole body protein turnover components were performed with the Kruskall-Wallis test; a graphical comparison of the 4 groups and outcomes was constructed with sideby-side box plots. We also calculated the Spearman correlation coefficient of hs-CRP (measured values) and the outcome values, and we calculated the associated test of no association. A series of scatterplots was generated to visualize the bivariate association. The covariate-adjusted association of hs-CRP and the outcomes were estimated with 2 linear regression models. Both models included age, log dialysis vintage, albumin, log FM, plasma bicarbonate, race, and sex, in addition to log hs-CRP. Model 1 also included an indicator for DM, whereas model 2 included HOMA-IR. Observations missing covariates listed in the model were excluded. To allow for the possibility that the effect of hs-CRP on the outcomes was not linear, hs-CRP was included into the regression models transformed as restricted cubic splines. To assess the impact of patients with DM on the results, we performed sensitivity analyses by refitting the regression 
models after excluding 29 patients who met the criteria for the presence of DM. The animal data were analyzed using two-sided student's $t$ test for comparisons between groups. We used the statistical software package R (version 3.3.3) for analyses. $P$ values of less than 0.05 were considered statistically significant.

\section{Study approval}

For all components of this study, ethical approvals were obtained from the IRB of Vanderbilt University and VATVHS-Nashville. The studies were conducted according to the principles set out in the Declaration of Helsinki. Written informed consent was obtained from all study patients. Mice were housed in a pathogen-free environment.

\section{Author contributions}

SMD participated in data collection and extraction, formulation of hypotheses, data analysis, and interpretation and writing of the manuscript. AMH participated in data collection, analysis and interpretation, and editing of the manuscript. JLG participated in data collection, analysis, and writing of the manuscript. EDS participated in data collection, extraction, analysis and interpretation, and editing of the manuscript. CDE participated in data collection and extraction and editing of the manuscript. CB participated in data collection and extraction and editing of the manuscript. FS participated in data collection, analysis and interpretation, and editing of the manuscript. HL participated in data collection, extraction, analysis and interpretation, and editing of the manuscript. $\mathrm{AB}$ participated in data analysis and interpretation and the writing and editing of the manuscript. TGS participated in data analysis and interpretation and in the editing of the manuscript. RZ participated in data collection, extraction, analysis and interpretation, and editing of the manuscript. WEM participated in data interpretation and editing of the manuscript. NNA participated in formulation of hypotheses, data analysis, and interpretation and editing of the manuscript. TAI participated in formulation of hypotheses, data collection, extraction, analysis and interpretation, and writing of the manuscript.

\section{Acknowledgments}

This study was in part supported by NIH grants R01 DK45604 and 1K24 DK62849 from the National Institute of Diabetes, Digestive and Kidney Diseases (TAI), the Clinical Translational Science Award UL1TR000445 from the National Center for Advancing Translational Sciences, the Veterans Administration Merit Award I01 CX000414 (TAI), the SatelliteHealth Normon Coplon Extramural Grant Program(TAI), and the FDA grant 000943 (TAI). SMD was in part supported by International Society of Nephrology and Turkish Society of Nephrology Fellowship grants.

Address correspondence to: T. Alp Ikizler, Vanderbilt University Medical Center, 1161 21st Avenue South \& Garland, Division of Nephrology, S-3223 MCN, Nashville, Tennessee 37232-2372, USA. Phone: 615.343.2220; Email: Alp.Ikizler@vanderbilt.edu.

1. Caglar K, et al. Inflammatory signals associated with hemodialysis. Kidney Int. 2002;62(4):1408-1416.

2. Pupim LB, Flakoll PJ, Majchrzak KM, Aftab Guy DL, Stenvinkel P, Ikizler TA. Increased muscle protein breakdown in chronic hemodialysis patients with type 2 diabetes mellitus. Kidney Int. 2005;68 (4):1857-1865.

3. Bailey JL, Wang X, England BK, Price SR, Ding X, Mitch WE. The acidosis of chronic renal failure activates muscle proteolysis in rats by augmenting transcription of genes encoding proteins of the ATP-dependent ubiquitin-proteasome pathway. $J$ Clin Invest. 1996;97 (6):1447-1453.

4. Yang J, Bowling JM, Lewis MA, Marshall SW, Runyan CW, Mueller FO. Use of discretionary protective equipment in high school athletes: prevalence and determinants. Am J Public Health. 2005;95 (11):1996-2002.

5. Pozzi A, et al. Beta1 integrin expression by podocytes is required to maintain glomerular structural integrity. Dev Biol. 2008;316 (2):288-301.

6. Zhang X, et al. beta1 integrin is necessary for ureteric bud branching morphogenesis and maintenance of collecting duct structural integrity. Development. 2009;136 (19):3357-3366

7. Saran R, et al. US Renal Data System 2015 Annual Data Report: Epidemiology of Kidney Disease in the United States. Am J Kidney Dis. 2016;67(3 Suppl 1):Svii, S1-Svii,305.

8. Moreau-Gaudry X, et al. A simple protein-energy wasting score predicts survival in maintenance hemodialysis patients. $J$ Ren Nutr. 2014;24 (6):395-400.

9. Carrero JJ, et al. Etiology of the protein-energy wasting syndrome in chronic kidney disease: a consensus statement from the International Society of Renal Nutrition and Metabolism (ISRNM). J Ren Nutr. 2013;23 (2):77-90.

10. Cano NJ, et al. Malnutrition in hemodialysis diabetic patients: evaluation and prognostic influence. Kidney Int. $2002 ; 62$ (2):593-601.

11. Ikizler TA. Optimal nutrition in hemodialysis patients. Adv Chronic Kidney Dis. 2013;20(2):181-189. 
12. Kalantar-Zadeh K, Block G, McAllister CJ, Humphreys MH, Kopple JD. Appetite and inflammation, nutrition, anemia, and clinical outcome in hemodialysis patients. Am J Clin Nutr. 2004;80 (2):299-307.

13. Bergström J, et al. What are the causes and consequences of the chronic inflammatory state in chronic dialysis patients? Semin Dial. 2000;13 (3):163-175.

14. Bistrian BR. Role of the systemic inflammatory response syndrome in the development of protein-calorie malnutrition in ESRD. Am J Kidney Dis. 1998;32 (6 Suppl 4):S113-S117.

15. Raj DS, et al. Coordinated increase in albumin, fibrinogen, and muscle protein synthesis during hemodialysis: role of cytokines. Am J Physiol Endocrinol Metab. 2004;286 (4):E658-E664.

16. Garibotto G, et al. Peripheral tissue release of interleukin-6 in patients with chronic kidney diseases: effects of end-stage renal disease and microinflammatory state. Kidney Int. 2006;70 (2):384-390

17. Pupim LB, Heimbürger O, Qureshi AR, Ikizler TA, Stenvinkel P. Accelerated lean body mass loss in incident chronic dialysis patients with diabetes mellitus. Kidney Int. 2005;68 (5):2368-2374.

18. Rozo M, Li L, Fan CM. Targeting $\beta 1$-integrin signaling enhances regeneration in aged and dystrophic muscle in mice. Nat Med. 2016;22 (8):889-896.

19. Takenaka T, Kanno Y, Ohno Y, Suzuki H. Key role of insulin resistance in vascular injury among hemodialysis patients. Metab Clin Exp. 2007;56 (2):153-159.

20. Ascaso JF, Pardo S, Real JT, Lorente RI, Priego A, Carmena R. Diagnosing insulin resistance by simple quantitative methods in subjects with normal glucose metabolism. Diabetes Care. 2003;26(12):3320-3325.

21. Gelfand RA, Barrett EJ. Effect of physiologic hyperinsulinemia on skeletal muscle protein synthesis and breakdown in man. $J$ Clin Invest. 1987;80(1):1-6.

22. Wolfe RR. Radioactive and Stable Isotope Tracers in Biomedicine: Principles and Practice of Kinetic Analysis. New York, New York, USA: Wiley-Liss; 1992:283-316.

23. Allsop JR, Wolfe RR, Burke JF. Tracer priming the bicarbonate pool. J Appl Physiol Respir Environ Exerc Physiol. 1978;45(1):137-139.

24. Garlick PJ, et al. Rates of nutrient utilization in man measured by combined respiratory gas analysis and stable isotopic labelling: effect of food intake. Hum Nutr Clin Nutr. 1987;41(3):177-191.

25. Brakebusch C, et al. Skin and hair follicle integrity is crucially dependent on beta 1 integrin expression on keratinocytes. $E M B O$ J. 2000;19 (15):3990-4003.

26. Raghavan S, Bauer C, Mundschau G, Li Q, Fuchs E. Conditional ablation of beta1 integrin in skin. Severe defects in epidermal proliferation, basement membrane formation, and hair follicle invagination. J Cell Biol. 2000;150 (5):1149-1160. 